\title{
Velocity of Climate Change and of Restoration Action: Collision Course?
}

\author{
Steven N. Handel
}

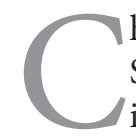
hange is expected in each restoration project. Sometimes the changes are simply growth of the individuals we bring to a site. Biomass increases, life history stages appear, and the number of individuals of the initial species increases. Changing growth can be accompanied by change in species composition. Sometimes ecological succession introduces new species through time; sometimes habitat disturbances eliminate some of the initial species and reshuffle the deck of community organization.

We often feel that a restoration project that does not change has failed; stasis in ecological structure is quite rare. If plants do not grow, effectively becoming bonsai, we question if the mix of species, soil, and microclimate has been miscalculated. If an animal fails to thrive onsite, we can question if the food web has been adequately prepared to nurture the growth and development needed for sustainability.

The speed of change in ecological communities is deliciously complex when we compare different locations or different habitat types. So many of our research studies are short-term. They are controlled by short funding cycles or by the short careers of graduate students. In contrast, the development of ecological communities can go on for many decades or hundreds of years. Recognition and monitoring of the unfolding story of habitat change can be obscure to workers whose projects, or even careers, are swift in comparison to natural habitat cycles.

Management of restoration projects must deal with these issues. Sometimes handing management over to the next generation of site managers may be the intelligent decision as critical transitions of habitat change may lie many years ahead. Layered over this process of ecological change is the current trajectory of rapid climate change. The velocity of this change has added an unwanted new problem to all of our work.

Although our journals and newspapers have concentrated on the intensity of climate change, the change varies across habitats and all local geographies. A series of recent

Ecological Restoration Vol. 33, No. 2, 2015

ISSN 1522-4740 E-ISSN 1543-4079

(O2015 by the Board of Regents of the University of Wisconsin System. papers (listed below) has developed the concept of climate change velocity. The rate and direction of temperature shifts will vary from time to time but also from place to place. This complexity will alter migration of species and interactions among species, whether as mutualists or competitors. This challenges our ability to properly plan for decades ahead as we manage regional biodiversity resources. Although the pattern of climate change has been projected over wide-scale geographies, the existing models are not accurate for specific small areas. However, it is at relatively small areas that our restoration activities occur. Will the changing climate be a temperature tsunami over our sites, or a slow and gentle rise?

In our own restoration work, we steel ourselves against failure which can come in so many ways. Inadequate site assessment is so common. We have neither time nor funds for long-term assessment before we install a new community. Routine weather variation hits us with periods of drought or heavy rains or too cold winters that cause high death rates in the initial communities on our sites. Similarly, no one can fully control onslaughts by non-natives insects or new invasive plants. We expect a certain rate of disappointment, even death of installed individuals. We plan for adequate population sizes to overcome this. Sometimes a reserve of funds or people-power can allow us to return and repair damage caused by shifts in the weather.

The reality of climate change velocity and its expressed pattern across the earth makes our work even more challenging. Some investigators casually assume that the normal climate from a few hundred kilometers south of their sites will reach them in a few decades. Plant palettes and management regimes get based on the southerly neighbors who are coming soon to visit ("Greetings, y-all."). But when the velocity of change is controlled by local topographic variation and proximity to water bodies, local conditions will change at different times during the coming decades. Planning for restoration success will have this layer of complexity to challenge hoped for ecological structure.

Biotic communication among nearby patches will also be affected as some areas will get warmer more quickly than others. Consequently, the landscape ecology will also change into a new mosaic of communities. Some patches will change quickly, like holiday lights flashing on and off 
at a high rate. Other patches will change more slowly, like a lightbulb that dims and one day fails as its element decays.

We fear that the velocity of understanding climate change will be slower than the isotherms themselves shifting across space. At a time when the need for restoration ecology and the many ecological services that accompany improved ecological structure have never been more important, practitioners may be on a slippery slope of new physical forces that trip us up as we seek to influence the biotic environment. This is still a time when political forces debate the reality of climate change. The evidence of shifting population ranges in both terrestrial and aquatic environments is quite substantial. The velocity of growing political will to accompany informed restoration is perhaps the slowest of the changes and one we need immediately as we envision a better future.

\section{Recommended References}

Burrows, M.T., D.S. Schoeman, L.B. Buckley, P. Moore, E.S. Poloczanska, K.M. Brander and A.J. Richardson. 2011. The pace of shifting climate in marine and terrestrial ecosystems. Science 334: 652-655.

Clewell, A., J. Rieger and J. Munro. 2005. Guidelines for Developing and Managing Ecological Restoration Projects, 2nd Ed. www.ser. org and Tucson: Society for Ecological Restoration International.

Loarie, S. R., P.B. Duffy, H. Hamilton, G.P. Asner, C.B. Field and D.D. Ackerly. 2009. The velocity of climate change. Nature 462: 1052-1055.

Maschinski, J. and K.E. Haskins. 2012. Plant Reintroduction in a Changing Climate: Promises and Perils. Washington, D.C.: Island Press.

Parmesan, C., N. Ryrholm, C. Stefanescu, J. K. Hill, C. D. Thomas, H. Descimon, B. Huntley, L. Kaila, J. Kullberg, T. Tammaru, W. J. Tennent, J. A. Thomas and M. Warren. 1999. Poleward shifts in geographical ranges of butterfly species associated with regional warming. Nature 399: 579-583.

Pinsky, M. L., B. Worm, M.J. Fogarty, J.L. Sarmiento and S.A. Levin. 2013. Marine taxa track local climate velocities. Science 341: 1239-1242.

Turner, R. M. 2003. The Changing Mile Revisited: an Ecological Study of Vegetation Change with Time in the Lower Mile of an Arid and Semiarid Region. Tucson, AZ: University of Arizona Press.

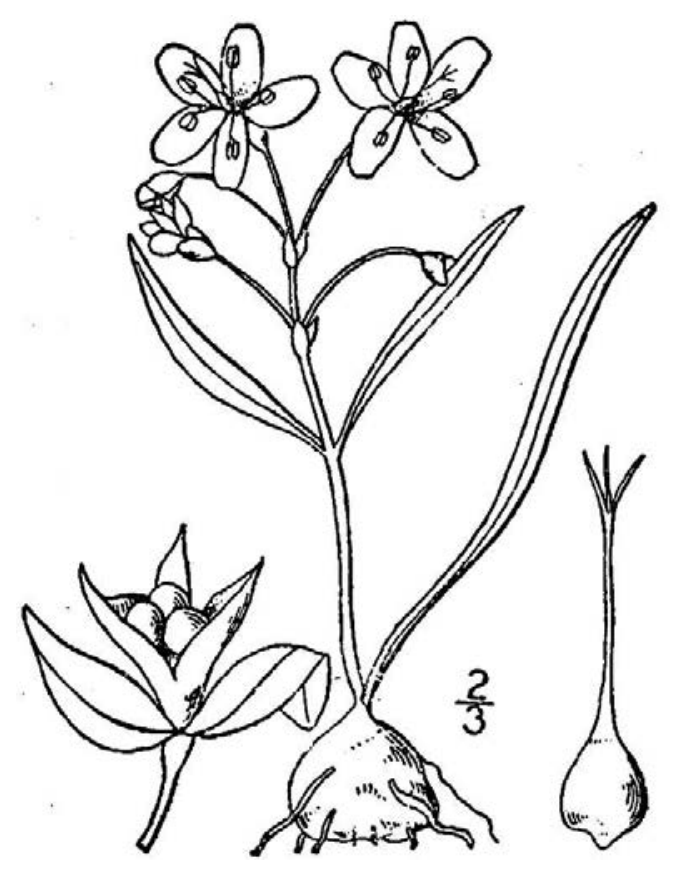

Claytonia virginica. USDA-NRCS PLANTS Database. Britton, N.L. and A. Brown. 1913. An illustrated flora of the northern United States, Canada and the British Possessions. New York, NY: Charles Scribner's Sons. 